\title{
Susceptibility of planktonic cultures of Streptococcus mutans to photodynamic therapy with a light-emitting diode
}

\author{
Anna Carolina Borges Pereira \\ da Costa(a) \\ José Chibebe Junior ${ }^{(a)}$ \\ Cristiane Aparecida Pereira(a) \\ Ana Karina da Silva Machado(a) \\ Milton Beltrame Junior ${ }^{(b)}$ \\ Juliana Campos Junqueira ${ }^{(a)}$ \\ Antonio Olavo Cardoso Jorge(a)
}

\begin{abstract}
(a) Department of Biosciences and Oral Diagnosis, School of Dentistry of São José dos Campos, UNESP - Univ. Estadual Paulista, São José dos Campos, SP, Brazil.

(b) Instituto de Pesquisa e DesenvolvimentoIP\&D, Universidade do Vale do Paraíba UNIVAP, São José dos Campos, SP, Brazil
\end{abstract}

Corresponding author:

Anna Carolina Borges Pereira da Costa Universidade Estadual Paulista (UNESP) Rua Francisco José Longo, 777, São Dimas

São José dos Campos - SP - Brazil CEP: 12245-000

E-mail:carolbbiolog@yahoo.com.br

Received for publication on Jun 12, 2010 Accepted for publication on Aug 06, 2010

\begin{abstract}
The objective of this study was to evaluate the effect of photodynamic therapy with erythrosine and rose bengal using a light-emitting diode (LED) on planktonic cultures of $S$. mutans. Ten $S$. mutans strains, including nine clinical strains and one reference strain (ATCC 35688), were used. Suspensions containing $10^{6}$ cells $/ \mathrm{mL}$ were prepared for each strain and were tested under different experimental conditions: a) LED irradiation in the presence of rose bengal as a photosensitizer $(\mathrm{RB}+\mathrm{L}+)$; b) LED irradiation in the presence of erythrosine as a photosensitizer $(\mathrm{E}+\mathrm{L}+)$; c) LED irradiation only $(\mathrm{P}-\mathrm{L}+)$; d) treatment with rose bengal only $(\mathrm{RB}+\mathrm{L}-)$; e) treatment with erythrosine only $(\mathrm{E}+\mathrm{L}-)$; and $\mathrm{f})$ no LED irradiation or photosensitizer treatment, which served as a control group $(\mathrm{P}-\mathrm{L}-)$. After treatment, the strains were seeded onto BHI agar for determination of the number of colony-forming units $(\mathrm{CFU} / \mathrm{mL})$. The results were submitted to analysis of variance and the Tukey test $(p \leq 0.05)$. The number of $\mathrm{CFU} / \mathrm{mL}$ was significantly lower in the groups submitted to photodynamic therapy $(\mathrm{RB}+\mathrm{L}+$ and $\mathrm{E}+\mathrm{L}+)$ compared to control $(\mathrm{P}-\mathrm{L}-)$, with a reduction of $6.86 \log _{10}$ in the $\mathrm{RB}+\mathrm{L}+$ group and of $5.16 \log _{10}$ in the $\mathrm{E}+\mathrm{L}+$ group. Photodynamic therapy with rose bengal and erythrosine exerted an antimicrobial effect on all $S$. mutans strains studied.
\end{abstract}

Descriptors: Streptococcus mutans; Photochemotherapy; Rose Bengal; Erythrosine.

\section{Introduction}

Mutans streptococci have raised interest because of their role in the etiology of caries. Streptococcus mutans and S. sobrinus are important agents involved in dental biofilm formation and are responsible for caries lesions. ${ }^{1}$ The dental biofilm is formed by the aggregation of microorganisms held together by a polysaccharide matrix. ${ }^{2}$ The ability of $S$. mutans to form a biofilm is mainly due to the secretion of glucosyltransferases that form polysaccharides, which confer adhesion properties to hard surfaces. $^{3}$

The control of caries is based on good oral hygiene and sugar abstention, which is achieved by mechanical removal of the biofilm and the use of chemical substances. New therapeutic strategies, such as photodynamic therapy (PDT) or photochemotherapy, are being developed in an attempt to control the population of cariogenic microorganisms in the oral cavity. ${ }^{4,5}$ PDT involves the topical or systemic administration of a 
non-toxic dye (photosensitizer) that is activated by exposure to visible light of an adequate wavelength in the presence of oxygen. ${ }^{6}$

The photosensitizers of the xanthene group, rose bengal and erythrosine, are cyclic compounds that contain three aromatic rings in a linear arrangement and an oxygen atom in the center of the ring, which absorbs light in the visible spectrum. ${ }^{6}$ Rose bengal is used in ophthalmology for the diagnosis of eye diseases. Its photodynamic mechanism consists of the formation of $80 \%$ singlet oxygen and $20 \%$ superoxide anion, with absorption of light in the 450-600 nm range. ${ }^{6,7}$ Erythrosine absorbs light in the visible region $(500-550 \mathrm{~nm})$ and is therefore able to initiate photochemical reactions. Its main application in dentistry is the demonstration of the presence of dental biofilms. ${ }^{4}$

A light source emitting light in the visible region and at a wavelength adequate for photosensitization is recommended for the irradiation of the dyes. The light-emitting diodes (LEDs) used in dentistry for the light-curing of restorative materials have been suggested as an alternative to the use of lasers because of their low cost and simplicity. ${ }^{5}$

Current options to reduce the population of cariogenic microorganisms are restricted to mechanical removal and the use of antiseptics. PDT might be an excellent alternative, or accessory therapy, for the control of caries. The objective of the present study was to evaluate the effect of PDT with erythrosine and rose bengal using an LED on planktonic cultures of $S$. mutans.

\section{Material and Methods}

The project was approved by the Ethics Committee of the School of Dentistry of São José dos Campos, Universidade Estadual Paulista (UNESP).

\section{Photosensitizer and light source}

Rose bengal and erythrosine (Sigma-Aldrich, Steinheim, Germany), both at a concentration of $2 \mu \mathrm{M}$, were used for the sensitization of $S$. mutans isolates. Each photosensitizer solution was prepared by dissolving the dye in phosphate-buffered saline (PBS), $\mathrm{pH} 7.4$, and followed by filtration through a sterile $0.22-\mu \mathrm{m}$ Millipore membrane (Millipore, São
Paulo, Brazil). After filtration, the photosensitizer solutions were stored in the dark.

The light source used was an LED (MMOptics, São Carlos, SP, Brazil) with a wavelength of 440$460 \mathrm{~nm}$, an output power of $200 \mathrm{~mW}$ and an illuminated area of $0.38 \mathrm{~cm}^{2}$. A fluence of $95 \mathrm{~J} . \mathrm{cm}^{-2}$ (energy of $36 \mathrm{~J}$ and time of $180 \mathrm{~s}$ ) and a fluence rate of $526 \mathrm{~mW} . \mathrm{cm}^{-2}$ were used.

The temperature monitoring at the bottom of the well was carried out with an infrared thermometer (MX4, Raytek, Sorocaba, Brazil), and no increase in the temperature was observed after the LED irradiation.

\section{Microorganisms}

Nine $S$. mutans strains previously isolated and identified from the oral cavity of healthy individuals and one reference strain (ATCC 35688) of S. mutans maintained in our laboratory stock collection were included in the study.

Standard suspensions of each isolate containing $10^{6}$ cells $/ \mathrm{mL}$ were prepared. For this purpose, isolates were seeded onto brain heart infusion (BHI) agar (Difco, Detroit, USA) and incubated for $48 \mathrm{~h}$ at $37^{\circ} \mathrm{C}$ under microaerophilic conditions. After incubation, the microorganisms were cultured in $\mathrm{BHI}$ broth (Difco) for $18 \mathrm{~h}$ at $37^{\circ} \mathrm{C}$ under microaerophilic conditions. All incubations were carried out at $37^{\circ} \mathrm{C}$ and at a partial pressure of $5 \% \mathrm{CO}_{2}$. The bacterial cultures were then centrifuged at $1300 \mathrm{xg}$ for $10 \mathrm{~min}$, and the supernatant was discarded. This procedure was repeated, and the sediment was resuspended in $10 \mathrm{~mL}$ sterile PBS.

The number of cells in each suspension was measured in a spectrophotometer (B582, Micronal, São Paulo, Brazil) at a wavelength of $398 \mathrm{~nm}$ and an optical density of 0.620 .

Using the standard suspension, 600 assays were carried out (60 assays per strain). The assays were divided into the following experimental conditions $(\mathrm{n}=10)$ :

a. LED irradiation using rose bengal as photosensitizer $(\mathrm{RB}+\mathrm{L}+)$;

b. LED irradiation using erythrosine as photosensitizer $(\mathrm{E}+\mathrm{L}+)$;

c. LED irradiation only $(\mathrm{P}-\mathrm{L}+)$; 
d. treatment with rose bengal only $(\mathrm{RB}+\mathrm{L}-)$;

e. treatment with erythrosine only $(\mathrm{E}+\mathrm{L}-)$; and

f. no LED irradiation or photosensitizer treatment $(\mathrm{P}-\mathrm{L}-)$.

\section{In vitro photosensitization}

According to the experimental conditions described above, $0.1 \mathrm{~mL}$ of the bacterial suspension was added to each well of sterile 96-well flat-bottom microtiter plates (Costar Corning, New York, USA). Next, $0.1 \mathrm{~mL}$ of the photosensitizer was added for groups $\mathrm{RB}+\mathrm{L}+$ or $\mathrm{E}+\mathrm{L}+$ and $\mathrm{RB}+\mathrm{L}-$ or $\mathrm{E}+\mathrm{L}-$, whereas $0.1 \mathrm{~mL}$ PBS was added for groups $\mathrm{P}-\mathrm{L}+$ and $\mathrm{P}-\mathrm{L}-$. The plates were shaken for $5 \mathrm{~min}$ (preirradiation time) in an orbital shaker (Solab, Piracicaba, Brazil). The well contents of groups $\mathrm{RB}+\mathrm{L}+$ or $\mathrm{E}+\mathrm{L}+$ and $\mathrm{P}-\mathrm{L}+$ were then irradiated according to the protocol described above. The distance between the light source and the bacterial cells was approximately $6 \mathrm{~mm}$. Irradiation was performed under aseptic conditions under a laminar flow hood in the dark. The plates were covered with a matte black screen with an orifice whose diameter corresponded to the size of the well entrance in order to prevent the spreading of light to neighboring wells.

After irradiation, serial dilutions were prepared, and $0.1 \mathrm{~mL}$ aliquots of each dilution were seeded in duplicate onto BHI agar plates and incubated for $48 \mathrm{~h}$ at $37^{\circ} \mathrm{C}$ under microaerophilic conditions. After incubation, the number of colony-forming units per milliliter $(\mathrm{CFU} / \mathrm{mL})$ was determined. The results were $\log$ transformed and analyzed by analysis of variance (ANOVA) and the Tukey test. A $p$ value $\leq 0.05$ was considered to indicate a statistically significant difference.

\section{Results}

Figure 1 shows the mean and standard deviation of the number of $\log _{10} \mathrm{CFU} / \mathrm{mL}$ obtained for the groups studied. PDT $(\mathrm{E}+\mathrm{L}+$ and $\mathrm{RB}+\mathrm{L}+)$ reduced $S$. mutans viability, whereas no reduction in microorganisms was observed for the groups treated with the photosensitizer only $(\mathrm{E}+\mathrm{L}-$ and $\mathrm{RB}+\mathrm{L}-)$ or irradiated in the absence of the dye $(\mathrm{P}-\mathrm{L}+)$ when compared to the control group (P-L-) (Table 1).

A significant difference was observed between the groups submitted to PDT (E+L+ and $\mathrm{RB}+\mathrm{L}+)$ and the other groups (Table 1). In addition, a significant difference between the $\mathrm{E}+\mathrm{L}+$ and $\mathrm{RB}+\mathrm{L}+$ groups was found for four strains, with a greater reduction of $\log _{10}$ CFU in the groups treated with rose bengal and irradiated with the LED (Table 1).

When compared to the control group ( $\mathrm{P}-\mathrm{L}-)$, there was a reduction of $5.16 \log _{10} \mathrm{CFU} / \mathrm{mL}$ in the $\mathrm{E}+\mathrm{L}+$ group and of $6.86 \log _{10} \mathrm{CFU} / \mathrm{mL}$ in the $\mathrm{RB}+\mathrm{L}+$ group.

\section{Discussion}

The present results demonstrated the antimicrobial efficacy of PDT using erythrosine and rose bengal against the ten $S$. mutans strains studied, including one reference strain (ATCC 35688) and nine $S$. mutans strains previously isolated from the oral cavities of different individuals. We chose to use these clinical strains of $S$. mutans so that the effects of PDT would be more biologically relevant. No significant difference in the number of CFU/mL was observed between the control group $(\mathrm{P}-\mathrm{L}-)$ and the groups treated in the dark with the photosensitizers only $(\mathrm{RB}+\mathrm{L}-$ and $\mathrm{E}+\mathrm{L}-)$ or the group irradiated in the absence of the dye $(\mathrm{P}-\mathrm{L}+)$. These findings agree with the basic principles of PDT, in which application of the dye or the light source alone has no anti-

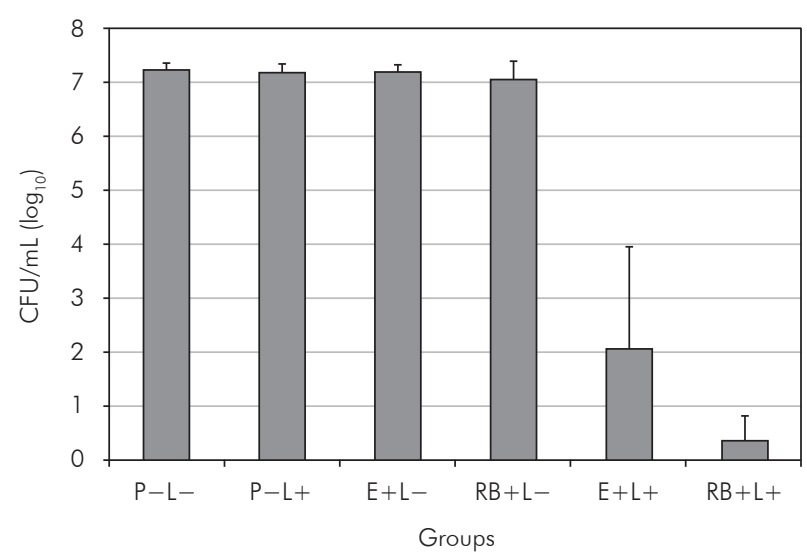

Figure 1 - Mean and standard deviation of the number of CFU/mL ( $\left.\log _{10}\right)$ obtained for the different groups: P-L- (not submitted to LED irradiation or photosensitizer); P-L+ (LED irradiation only); $\mathrm{E}+\mathrm{L}-$ (treatment with erythrosine only); $\mathrm{RB}+\mathrm{L}-$ (treatment with rose bengal only); $\mathrm{E}+\mathrm{L}+$ (LED irradiation using erythrosine as photosensitizer); RB $+\mathrm{L}+$ (LED irradiation using rose bengal as photosensitizer). 


\begin{tabular}{|c|c|c|c|c|c|c|c|}
\hline \multirow{3}{*}{$\begin{array}{l}\text { Table } 1 \text { - Number of colony- } \\
\text { forming units per milliliter } \\
(\mathrm{CFU} / \mathrm{mL})\left(\log _{10}\right) \text { obtained for } \\
\text { ten strains per group. }\end{array}$} & \multirow{2}{*}{ Strains } & \multicolumn{6}{|c|}{ CFU/mL $\left(\log _{10}\right)$} \\
\hline & & $\mathrm{P}-\mathrm{L}-$ & $\mathrm{P}-\mathrm{L}+$ & $\mathrm{E}+\mathrm{L}-$ & $\mathrm{RB}+\mathrm{L}-$ & $\mathrm{E}+\mathrm{L}+$ & $\mathrm{RB}+\mathrm{L}+$ \\
\hline & 111025 & $7.31^{\mathrm{A}}$ & $7.30^{A}$ & $7.31^{\mathrm{A}}$ & $7.29^{\mathrm{A}}$ & $0.00^{\mathrm{B}}$ & $0.00^{\mathrm{B}}$ \\
\hline & 111031 & $7.30^{\mathrm{A}}$ & $7.30^{\mathrm{A}}$ & $7.32^{A}$ & $6.86^{A}$ & $2.10^{B}$ & $1.13^{\mathrm{B}}$ \\
\hline & 111030 & $7.16^{A}$ & $7.15^{\mathrm{A}}$ & $7.15^{\mathrm{A}}$ & $7.00^{\mathrm{A}}$ & $1.10^{\mathrm{B}}$ & $1.00^{\mathrm{B}}$ \\
\hline & 111026 & $7.29^{A}$ & $7.30^{A}$ & $7.31^{\mathrm{A}}$ & $7.29^{\mathrm{A}}$ & $0.62^{\mathrm{B}}$ & $0.62^{\mathrm{B}}$ \\
\hline & 111015 & $6.90^{\mathrm{A}}$ & $6.90^{\mathrm{A}}$ & $7.22^{A}$ & $6.24^{\mathrm{A}}$ & $0.66^{\mathrm{B}}$ & $0.00^{\mathrm{B}}$ \\
\hline & 111029 & $7.22^{A}$ & $7.24^{\mathrm{A}}$ & $7.25^{A}$ & $7.27^{A}$ & $4.46^{\mathrm{B}}$ & $0.40^{c}$ \\
\hline & 111028 & $7.31^{\mathrm{A}}$ & $7.28^{A}$ & $7.30^{A}$ & $7.15^{\mathrm{A}}$ & $3.86^{B}$ & $0.00^{c}$ \\
\hline & 111024 & $7.31^{\mathrm{A}}$ & $7.22^{\mathrm{A}}$ & $6.97^{A}$ & $7.26^{\mathrm{A}}$ & $2.70^{\mathrm{B}}$ & $0.00^{c}$ \\
\hline & 111023 & $7.34^{\mathrm{A}}$ & $7.29^{A}$ & $7.18^{A}$ & $7.28^{\mathrm{A}}$ & $5.11^{\mathrm{B}}$ & $0.47^{c}$ \\
\hline & ATCC 35688 & $7.04^{\mathrm{A}}$ & $6.95^{\mathrm{A}}$ & $7.00^{A}$ & $7.00^{\mathrm{A}}$ & $0.00^{\mathrm{B}}$ & $0.00^{\mathrm{B}}$ \\
\hline
\end{tabular}

$A, B$ and $C$ : the differences between values marked with different letters are statistically significant (Tukey test, $p \leq 0.05)$.

bacterial effect. ${ }^{8}$

In the present study, rose bengal was used as a photosensitizer at a concentration of $2 \mu \mathrm{M}$ for the treatment of $S$. mutans suspensions containing $10^{6}$ cells $/ \mathrm{mL}$. Paulino et al. ${ }^{7}$ investigated the toxicity of rose bengal at concentrations of $0-10 \mu \mathrm{M}$ to $S$. mutans at a cell density of $10^{3} \mathrm{CFU} / \mathrm{mL}$, and they showed that rose bengal is not toxic at concentrations lower than $5.0 \mu \mathrm{M}$. In another study, the same authors observed that the application of rose bengal concentrations lower than $5.0 \mu \mathrm{M}$ in the dark were also not toxic to fibroblasts. ${ }^{9}$

A study on the safety of topical rose bengal showed that the dye was unable to penetrate beyond the epidermis. Thus, the authors proposed the topical dermatological use of rose bengal for various diagnostic applications of the dye, such as the use of $9.8 \mathrm{mM}$ rose bengal for the diagnosis of dry eye, a concentration approximately 5,000 times higher than that used in the present study. ${ }^{10}$

Erythrosine is used in dental practice for the detection of dental biofilms at concentrations of 9-25 mM, i.e., at concentrations approximately 10,000 times higher than that used in the present study. ${ }^{11}$ Erythrosine presents advantages over other photosensitizers since it is not toxic to the host and has already been approved for use in dentistry. ${ }^{4,12}$ Moreover, we did not find in the literature any papers describing the effect of PDT with erythrosine and blue a LED on planktonic cultures of S. mutans.

Studies have demonstrated that the use of LEDs alone exerts little or no microbicidal activity. ${ }^{5,13}$ This light source is employed for the light-curing of restorative materials and is therefore not damaging to oral tissues. In addition, LEDs present the following advantages over lasers: they are smaller and lighter equipment; are lower cost; have a broad spectrum output, resulting in greater flexibility during irradiation; and are easy to operate. ${ }^{14,15}$

A significant reduction in $S$. mutans was observed in the groups submitted to PDT $(\mathrm{RB}+\mathrm{L}+$ and $\mathrm{E}+\mathrm{L}+$ ) when compared to the other groups. According to literature, rose bengal and erythrosine absorb light in the $450-600 \mathrm{~nm}$ and $500-550 \mathrm{~nm}$ ranges, respectively, and the light source used in the present study emits light in the 440-460 range. These data could explain the fact that better results were obtained for rose bengal than for erythrosine. ${ }^{4,7}$ The association between the dyes and light resulted in cellular death, probably due to the generation of reactive oxygen species. The use of LEDs in PDT is advantageous primarily because of their safety for use in dentistry and their availability in the dentist's office.

Significant differences between PDT with rose bengal and erythrosine were observed for four $S$. mutans strains, with the results suggesting that rose bengal was more effective in photodynamic inacti- 
vation than erythrosine was. Rose bengal is a type II photosensitizer that exhibits easy photocatalytic conversion of triplet oxygen into singlet oxygen. The latter reactive oxygen species causes damage to unsaturated fatty acids present in lipid membranes that undergo peroxidation reactions, to enzymes by specific reactions with the amino acids methionine, tryptophan and tyrosine, and to nucleic acids by initial interaction with guanine bases. ${ }^{16}$ These effects result in bacterial death since antioxidant enzymes such as superoxide dismutase and catalase protect against some oxygenated radicals but not against singlet oxygen. ${ }^{14}$

In the present study, a mean reduction of $6.86 \log _{10}$ CFU/mL was observed for bacterial suspensions treated with rose bengal and irradiated with the LED. Paulino et al. ${ }^{9}$ also demonstrated the photodynamic activity of rose bengal on planktonic cultures of $S$. mutans, with a concentration of $0.5 \mu \mathrm{M}$ of the photosensitizer resulting in a $3-\log _{10}$ reduction of cells irradiated with a hand-held photopolymerizer. Comparing the results of these works, the most suitable source light for rose bengal-mediated PDT was decided to be the LED emitting blue light, which demonstrated a higher reduction in the number of cells than the handheld photopolymerizer did.

The microbial reduction observed in the group treated with erythrosine and irradiated with the LED was $5.16 \log _{10}$. This result agrees with the studies of Wood et al. ${ }^{4}$ and Metcalf et al. ${ }^{17}$ Wood et al. ${ }^{4}$ evaluated the photodynamic activity of erythrosine, methylene blue and photophrin irradiated with a tungsten-filament lamp on $S$. mutans biofilms. Erythrosine $(22 \mu \mathrm{M})$ was found to be the most effective photosensitizer, resulting in a $2.2-\log _{10}$ reduction for 24 -h biofilms and a $3.0-\log _{10}$ reduction for 288-h biofilms. Metcalf et al. ${ }^{17}$ demonstrated that fractionation of white light during irradiation of $S$. mutans biofilms treated with $22 \mu \mathrm{M}$ erythrosine increased bacterial killing by $1.7 \log _{10}$ when compared to continuous light irradiation.

LEDs have been used in PDT as an alternative light source to lasers. Bevilacqua et al. ${ }^{13}$ reported efficacy (7.91- $\log _{10}$ reduction) in the killing of plank- tonic $S$. mutans cultures irradiated with an LED at a wavelength of $640 \mathrm{~nm}$ in the presence of toluidine blue as photosensitizer. Zanin et al. ${ }^{5}$ evaluated the in vitro susceptibility of $S$. mutans biofilms to PDT. After pre-irradiation treatment with toluidine blue for 5, 15 and $30 \mathrm{~min}$, the biofilms were irradiated with an LED (620-660 nm) and HeNe laser (632.8 nm). The reductions in cell viability ranged from 3.12 to $4.29 \log _{10}$ and from 2.10 to $3.1 \log _{10}$, respectively. However, the LED combined with toluidine blue was more effective than treatment with the $\mathrm{HeNe}$ laser, thus indicating the potential of LEDs in PDT for the treatment of oral diseases since the safety of LEDs have been demonstrated for oral tissues.

The application of antimicrobial photodynamic therapy is promising because the development of resistance after multiple treatments is unlikely due to the interaction of singlet oxygen and free radicals with various cellular structures and different metabolic pathways. In addition, PDT is equally effective against antibiotic-resistant and antibiotic-susceptible bacteria and is not mutagenic. ${ }^{14,18}$

The oral cavity is an adequate site for the application of PDT because it is accessible to illumination. ${ }^{14}$ Additional advantages of PDT include reductions in treatment time and in the occurrence of side effects, which are frequently observed after the systemic administration of antibiotics, and the lower cost of treatment. ${ }^{19}$ PDT is an alternative or complementary tool for the treatment of oral diseases such as caries in situations in which antimicrobial therapy is ineffective or not recommended and in which mechanical removal is not possible.

\section{Conclusion}

In vitro PDT with rose bengal and erythrosine using an LED exerted antimicrobial activity on planktonic cultures of $S$. mutans.

\section{Acknowledgements}

The financial support of the Fundação de Amparo à Pesquisa do Estado de São Paulo (FAPESP), grant n. 09/52048-1, is gratefully acknowledged. We would also like to thank MMOptics for kindly providing the LED device used in this study. 


\section{References}

1. Ge Y, Caufield PW, Fish GS, Li Y. Streptococcus mutans and Streptococcus sanguinis colonization correlated with caries experience in children. Caries Res. 2008;42(6):444-8.

2. Ahn SJ, Ahn SJ, Wen ZT, Brady J, Burne RA. Characteristics of biofilm formation by Streptococcus mutans in the presence of saliva. Infect Immun. 2008 Sep;76(9):4259-68.

3. Almeida PF, Franca MP, Santos SP, Moreira RS, Tunes UR. Microbiota estreptocócica associada com a formação inicial da placa dental. Rev Cienc Med Biol. 2002 Nov;1(1):33-41.

4. Wood S, Metcalf D, Devine D, Robinson C. Erythrosine is a potential photosensitizer for the photodynamic therapy of oral plaque biofilms. J Antimicrob Chemother. 2006 Apr;57(4):680-4.

5. Zanin ICJ, Gonçalves RB, Brugnera Jr A, Hope CK, Pratten J. Susceptibility of Streptococcus mutans biofilms to photodynamic therapy: an in vitro study. J Antimicrob Chemother. 2005 Aug;56(2):324-30.

6. Perussi JR. Inativação fotodinâmica de microrganismos. Quim Nova. 2007 Aug;304(4):988-94.

7. Paulino TP, Magalhães PP, Thedei Jr G, Tedesco AC, Ciancaglini P. Use of visible light-based photodynamic therapy to bacterial photoinactivation. Biochem Mol Biol Educ. 2005 Jan;33(1):46-9.

8. Pleatzer K, Krammer B, Berlanda J, Berr F, Kiesslich T. Photophysics and photochemistry of photodynamic therapy: fundamental aspects. Lasers Med Sci. 2009 Mar;24(2):259-68.

9. Paulino TP, Ribeiro KF, Thedei Jr G, Tedesco AC, Ciancaglini P. Use of hand held photopolymerizer to photoinactivate Streptococcus mutans. Arch Oral Biol. 2005 Mar;50(3):353-9.
10. Wachter E, Dees C, Harkins J, Scott T, Petersen M, Rush RE, et al. Topical rose bengal: pre-clinical evaluation of pharmacokinetics and safety. Lasers Surg Med. 2003;32(2):101-10.

11. Marsh PD, Bevis RA, Newman HN, Hallsworth AS, Robinson C, Weatherell JA, et al. Antibacterial activity of some plaquedisclosing agents and dyes. Caries Res. 1989;23(5):348-50.

12. Allaker RP, Douglas CWI. Novel anti-microbial therapies for dental plaque-related diseases. Int J Antimicrob Agents. 2009 Jan;33(1):8-13.

13. Bevilacqua IM, Nicolau RA, Khouri S, Brugnera Jr A, Teodoro GR, Zângaro RA, et al. The impact of photodynamic therapy on the viability of Streptococcus mutans in a planktonic culture. Photomed Laser Surg. 2007 Dec;256(6):513-8.

14. Konopka K, Goslinski T. Photodynamic therapy in dentistry. J Dent Res. 2007 Aug;86(8):694-707.

15. Meisel P, Kocher T. Photodynamic therapy for periodontal diseases: state of the art. J Photochem Photobiol B. 2005 May;79(2):159-70.

16. Banks JG, Board RG, Carter J, Dodge AD. The cytotoxic and photodynamic inactivation of micro-organisms by rose Bengal. J Appl Bacteriol. 1985 Apr;58(4):391-400.

17. Metcalf D, Robinson C, Devine D, Wood S. Enhancement of erythrosine-mediated photodynamic therapy of Streptococcus mutans biofilms by light fractionation. J Antimicrob Chemother. 2006 Jul;58(1):190-2.

18. Maisch T. Anti-microbial photodynamic therapy: useful in the future? Lasers Med Sci. 2007 Jun;22(2):83-91.

19. O'Riordan K, Akilov OE, Hasan T. The potential for photodynamic therapy in the treatment of localized infections. Photodiagnosis Photodyn Ther. 2005 Dec; 2(4):247-62. 